\title{
Antimicrobials Are a Photodynamic Inactivation Adjuvant for the Eradication of Extensively Drug-Resistant Acinetobacter baumannii
}

\author{
Agata Wozniak ${ }^{1}$, Aleksandra Rapacka-Zdonczyk ${ }^{1}$, Nico T. Mutters ${ }^{2}$ and \\ Mariusz Grinholc ${ }^{1 *}$ \\ 'Laboratory of Molecular Diagnostics, Department of Biotechnology, Intercollegiate Faculty of Biotechnology, University \\ of Gdańsk and Medical University of Gdańsk, Gdańsk, Poland, ${ }^{2}$ Institute for Infection Prevention and Hospital Epidemiology, \\ Medical Center - Faculty of Medicine, University of Freiburg, Freiburg, Germany
}

OPEN ACCESS

Edited by:

Fabian Cieplik,

Universitätsklinikum Regensburg,

Germany

Reviewed by:

Tianhong Dai,

Massachusetts General Hospital, Harvard Medical School,

United States

Tim Maisch

University of Regensburg, Germany

${ }^{*}$ Correspondence:

Mariusz Grinholc

mariusz.grinholc@biotech.ug.edu.pl

Specialty section:

This article was submitted to Antimicrobials, Resistance

and Chemotherapy,

a section of the journal

Frontiers in Microbiology

Received: 09 October 2018 Accepted: 28 January 2019

Published: 13 February 2019

Citation:

Wozniak A, Rapacka-Zdonczyk A, Mutters NT and Grinholc M (2019) Antimicrobials Are a Photodynamic Inactivation Adjuvant for the Eradication of Extensively

Drug-Resistant Acinetobacter baumannii. Front. Microbiol. 10:229. doi: 10.3389/fmicb.2019.00229
The worldwide emergence of extensively drug resistant (XDR) Acinetobacter baumannii has reduced the number of antimicrobials that exert high bactericidal activity against this pathogen. This is the reason why many scientists are focusing on investigations concerning novel non-antibiotic strategies such as antimicrobial photodynamic inactivation (aPDI) or the use of antimicrobial blue light (aBL). Therefore, the aim of the current study was to screen for antimicrobial synergies of routinely used antibiotics and phototherapies, including both aPDI involving exogenously administered photosensitizing molecules, namely, rose bengal, and $\mathrm{aBL}$, involving excitation of endogenously produced photoactive compounds. The synergy testing was performed in accordance with antimicrobial susceptibility testing (AST) standards, including various methodological approaches, i.e., antibiotic diffusion tests, checkerboard assays, CFU counting and the evaluation of postantibiotic effects (PAEs). We report that combining antimicrobials and $\mathrm{aPDI} / \mathrm{aBL}$ treatment led to a new strategy that overcomes drug resistance in XDR $A$. baumannii, rendering this pathogen susceptible to various categories of antibiotics. Sublethal aPDI/aBL treatment in the presence of sub-MIC levels of antimicrobials effectively killed $A$. baumannii expressing drug resistance to studied antibiotics when treated with only antibiotic therapy. The susceptibility of XDR A. baumannii to a range of antibiotics was enhanced following sublethal aPDI/aBL. Furthermore, $3^{\prime}$-(p-aminophenyl) fluorescein (APF) testing indicated that significantly increased reactive oxygen species production upon combined treatment could explain the observed synergistic activity. This result represents a conclusive example of the synergistic activity between photodynamic inactivation and clinically used antimicrobials leading to effective eradication of XDR A. baumannii isolates and indicates a potent novel therapeutic approach.

Keywords: Acinetobacter baumannii, antimicrobials, antimicrobial blue light, photodynamic inactivation, rose bengal, synergy 


\section{INTRODUCTION}

Acinetobacter baumannii is a threatening human pathogen. A key component of its pathogenicity is its outstanding capability to acquire resistance (Spellberg and Bonomo, 2014). Pan-drug resistant (PDR) strains that express resistance to all clinically available antibiotics are of particular concern (Valencia et al., 2009). A lack of effective antimicrobials has forced the need for the development of novel strategies to control A. baumannii infections. One of these approaches is antimicrobial photodynamic inactivation (aPDI) or antimicrobial blue light (aBL) (Nitzan et al., 1998; Dai et al., 2009; Cai et al., 2012; Huang et al., 2014; Yuan et al., 2017; Yang et al., 2018). These strategies exert high bactericidal efficacy toward various microbes regardless of antibiotic resistance. Moreover, the acquisition of resistance to such a method is unlikely due to the nature of the multi-targeted process (Maisch, 2015). Briefly, the mechanism of aPDI involves a combination of non-toxic photosensitizers (PSs) and visible light (Wainwright, 1998). In the presence of oxygen, light induces the formation of reactive oxygen species (ROS) by energy or electron transfer from the PS excited state; these ROS can oxidize numerous cell biomolecules, leading to bacterial killing (Grinholc et al., 2015).

The most recent discoveries concerning aPDI or aBL indicates that photoinactivation renders microbes susceptible to clinically used antimicrobial agents (Wozniak and Grinholc, 2018). Nevertheless, only limited studies aimed at analyzing the synergistic interactions between bactericidal approaches have complied with the standards imposed for scientific literature. Thus, it was barely possible to draw reliable conclusions indicating possible synergies between photoinactivation and antimicrobials. Photoinactivation of microorganisms can damage the cell envelope, genetic material or both simultaneously (Grinholc et al., 2015); thus, in the present study, we focused on analyzing whether the synergistic effect between aPDI/aBL and antimicrobials occurs and whether it is influenced by the administration of an exogenous PS such as rose bengal (RB) or thus of endogenously produced PSs such as porphyrins, which we excited with very intense blue light (aBL). Next, to provide accurate and reliable evidence that photoinactivation indeed renders microbes susceptible to antimicrobials and acts synergistically with antibiotics, in the current work, two XDR A. baumannii isolates together with numerous synergy testing assays guidelines from the European Committee on Antimicrobial Susceptibility Testing (EUCAST) and the Clinical Laboratory and Standards Institute (CLSI) were employed. In addition, within the current study, the interaction of aPDI/aBL with chemotherapeutic agents (from all antibiotic classes and covering all mechanisms of action) listed by the National and European Centers for Antimicrobial Susceptibility Testing (AST) was investigated.

\section{MATERIALS AND METHODS}

\section{Strains and Culture Conditions}

Acinetobacter baumannii strains (no. 127, 128) were isolated from tracheal secretions and wounds from ICU patients at
University Medical Center Freiburg. The profiles of resistance showed that both strains have XDR profiles (Magiorakos et al., 2012). A. baumannii strains were cultivated at $37^{\circ} \mathrm{C}$ in tryptic soy broth (TSB, bioMérieux, France) for $16-20 \mathrm{~h}$ under aerobic conditions in an orbital incubator (Innova 40, Brunswick, Germany) at $150 \mathrm{rpm}$. Moreover, two ATCC reference strains were used as a quality control for AST, i.e., P. aeruginosa ATCC 27853 and Escherichia coli ATCC 25922.

\section{Antimicrobial Susceptibility Testing (AST)}

AST protocols followed EUCAST guidelines. The antimicrobial agents listed in Table 1 were used (Sigma-Aldrich, Germany). For AST, ETEST $^{\mathrm{TM}}$ (bioMérieux, France) and Sensi-Disc ${ }^{\mathrm{TM}}$ (Becton Dickinson, United States) were used. Each experiment was performed in three repetitions at different time. Interpretation of the results was performed using EUCAST breakpoint tables (Version 8.1).

\section{Minimal Inhibitory Concentration of aBL/aPDI}

The minimal inhibitory dose of aBL and aPDI was defined as the amount of light and/or PS that inhibits the growth of bacteria under experimental conditions complementary to the AST. For aBL, light with a wavelength of $411 \mathrm{~nm}$ was used; for aPDI treatment, the light at $515 \mathrm{~nm}$ and RB (5 $\mu \mathrm{M})$ were used. Overnight bacterial cultures were adjusted in fresh MHB medium to $0.5 \mathrm{McF}$ arland, 10-fold diluted and finally transferred with or without PS to a 96-well plate. For MIC estimation of aBL, light $\left(18.2,36.4,54.5,72.7,90.9 \mathrm{~J} / \mathrm{cm}^{2}\right)$ was delivered for three independent biological samples. In the case of the MIC of aPDI, light doses of $20,40,60,70,80,90$, and $100 \mathrm{~J} / \mathrm{cm}^{2}\left(70 \mathrm{~mW} / \mathrm{cm}^{2}\right)$ were delivered to three independent biological samples. After phototreatment, plates were kept in dark at $37^{\circ} \mathrm{C}$ for $16-20 \mathrm{~h}$ (Termaks, Norway), followed by aBL/aPDI MIC determination via measuring the medium turbidity.

\section{Light Sources}

Illumination was performed with two light-emitting diode (LED) light sources, emitting blue $\left(\lambda_{\max } 411 \mathrm{~nm}\right.$, irradiance $130 \mathrm{~mW} / \mathrm{cm}^{2}$, full width at half maximum (FWHM) $17 \mathrm{~nm}$ ) and green light $\left(\lambda_{\max } 515 \mathrm{~nm}\right.$, irradiance $70 \mathrm{~mW} / \mathrm{cm}^{2}$, FWHM $33 \mathrm{~nm}$ ) (SecureMedia, Poland). The full characteristics of the light sources were recently published by Ogonowska et al. (2018).

\section{Photosensitizer}

RB [4,5,6,7-tetrachloro-2', $4^{\prime}, 5^{\prime}, 7^{\prime}$-tetraiodofluorescein disodium salt (Sigma-Aldrich, Germany)] was dissolved in sterile water at a $1 \mathrm{mM}$ concentration and kept in the dark at $-20^{\circ} \mathrm{C}$. For photodynamic inactivation, $\mathrm{RB}$ was used in two final concentrations, 5 and $10 \mu \mathrm{M}$.

\section{aBL/aPDI Treatment}

Overnight bacterial cultures adjusted to $5 \times 10^{7} \mathrm{CFU} / \mathrm{ml}$ were transferred to a 96-well plate alone or in combination with PS. The aPDI samples treated with $\mathrm{RB}$ were incubated at room temperature in the dark $(15 \mathrm{~min})$ and then irradiated with 
TABLE 1 | Minimal inhibitory concentrations for antimicrobials and light conditions.

\begin{tabular}{|c|c|c|c|c|}
\hline \multirow[t]{2}{*}{ Antibiotic target } & \multirow[t]{2}{*}{ Antimicrobial category } & \multirow[t]{2}{*}{ Antibiotic } & \multirow{2}{*}{$\begin{array}{l}\text { A. baumannii } 127 \\
\operatorname{MIC}[\mu \mathrm{g} / \mathrm{ml}]^{\mathrm{a}}\end{array}$} & \multirow{2}{*}{$\begin{array}{c}\text { A. baumannii } 128 \\
\text { MIC }[\mu \mathrm{g} / \mathrm{ml}]\end{array}$} \\
\hline & & & & \\
\hline \multirow[t]{4}{*}{ Protein synthesis (50S) } & Lincosamides & Clindamycin & & \\
\hline & Macrolides & Erythromycin & & \\
\hline & Phenicols & Chloramphenicol & & \\
\hline & Streptogamins & Quinupristin-dalfopristin & & \\
\hline \multirow[t]{4}{*}{ Protein synthesis (30S) } & Aminoglycosides & Gentamycin & $1024(\mathrm{R})$ & $1024(R)$ \\
\hline & Tetracyclines & Doxycycline (NR) & 32 & 64 \\
\hline & Aminoglycosides & Tobramycin & $\geq 16(\mathrm{R})$ & $\geq 16(\mathrm{R})$ \\
\hline & Glycylcyclines & Tigecycline & & \\
\hline $70 S$ initiation complex & Oxazolidinones & Linezolid & & \\
\hline Folic acid metabolism & Folate pathway inhibitors & $\begin{array}{l}\text { Trimethoprim- } \\
\text { sulfamethoxazole }\end{array}$ & $512(R)$ & $1024(R)$ \\
\hline DNA-directed RNA polymerase & Ansamycins & Rifampicin & & \\
\hline DNA gyrase & Fluoroquinolones & Ciprofloxacin & $32(\mathrm{R})$ & $128(R)$ \\
\hline \multirow[t]{8}{*}{ Cell-wall synthesis } & Carbapenems & Imipenem & $32(\mathrm{R})$ & $32(\mathrm{R})$ \\
\hline & $\begin{array}{l}\text { Antipseudomonal penicillins }+ \\
\beta \text {-lactamase inhibitor }\end{array}$ & Piperacillin-tazobactam & 512 & 256 \\
\hline & Extended-spectrum cephalosporins & Ceftazidime (NR) & 512 & 256 \\
\hline & Penicillins $+\beta$-lactamase inhibitor & Ampicillin-sulbactam & 128 & 64 \\
\hline & Extended-spectrum cephalosporins & Cefotaxime & & \\
\hline & Carbapenems & Meropenem & $\geq 16(R)$ & $\geq 16(\mathrm{R})$ \\
\hline & Phosphonic acid & Fosfomycin & & \\
\hline & Monobactam & Aztreonam & & \\
\hline \multirow[t]{2}{*}{ Cell membrane } & Polymyxins & Colistin & $2(\mathrm{~S})$ & $2(\mathrm{~S})$ \\
\hline & & & \multicolumn{2}{|c|}{ Light dose $\left[\mathrm{J} / \mathrm{cm}^{2}\right]$} \\
\hline \multirow[t]{2}{*}{ Phototherapy } & $\mathrm{aBL}$ & Blue light (411 nm) & 72.7 & 72.7 \\
\hline & aPDI & $\begin{array}{l}\text { Green light }(515 \mathrm{~nm})+ \\
\text { rose bengal }(5 \mu \mathrm{M})\end{array}$ & 80 & 90 \\
\hline
\end{tabular}

$N R$, not recommended; S, susceptible; $R$, resistant. ${ }^{a}$ MIC values were determined within the current study.

different light doses up to $300 \mathrm{~J} / \mathrm{cm}^{2}$. The aBL samples without $\mathrm{RB}$ were illuminated with different light doses, with the highest value being $109.1 \mathrm{~J} / \mathrm{cm}^{2}$. After illumination, a $10-\mu$ l aliquot was transferred to PBS, serially diluted and streaked horizontally on TSA plates. The control consisted of untreated bacteria. TSA plates were incubated at $37^{\circ} \mathrm{C}$ for $16-20 \mathrm{~h}$, and then $\mathrm{CFU}$ were counted. Each experiment was performed in three independent replicates.

\section{Determination of the Sublethal and Lethal Doses of aBL/aPDI}

Estimation of the sublethal (reduction of $0.5-2 \log _{10}$ in CFU/ml) and lethal (reduction $\geq 3 \log _{10}$ in $\mathrm{CFU} / \mathrm{ml}$ ) photodynamic (aBL/aPDI) treatments were assessed as the changes in survival rate of treated bacteria vs. untreated bacteria (Barry and Lasner, 1979; Dodd et al., 1997; Kohanski et al., 2010; Latimer et al., 2012; Andersson and Hughes, 2014; Amin et al., 2016; Fila et al., 2018).

\section{Synergy Testing}

There are only a few approved methods for synergy testing that give reliable results, according to the American Society for
Microbiology $y^{1}$ (i) disk diffusion assay; (ii) ETEST; (iii) time-kill assay [e.g., PAE (postantibiotic effect)]; and (iv) checkerboard assay (Doern, 2014). For experiments involving aPDI/aBL and antimicrobials, all of the recommended methods were used, and the survival rate of bacterial cells $(\mathrm{CFU} / \mathrm{ml})$ and the optical density $\left(\mathrm{OD}_{580}\right)$ were determined.

\section{Diffusion Assays}

Bacterial cultures $\left(5 \times 10^{6} \mathrm{CFU} / \mathrm{ml}\right)$ were ready to use within 15 min of preparation. For experiments concerning the combined aPDI treatment, the bacterial cultures were transferred to 24-well plates with RB ( $1 \mathrm{ml}$ per well) to receive a final PS concentration of 5 or $10 \mu \mathrm{M}$ and then incubated for $15 \mathrm{~min}$. Next, samples were treated with $515 \mathrm{~nm}$ light. In the case of aBL, the bacterial cultures were irradiated with $411 \mathrm{~nm}$ light. After phototreatment, samples were streaked on Mueller-Hinton agar plates (MHE, bioMerieux, France). Then, Sensi-Discs ${ }^{\mathrm{TM}}$ and ETESTs were placed on MHE agar plates and incubated for the next 15 min at room temperature. Next, plates were incubated at $37^{\circ} \mathrm{C}$ for $16 \mathrm{~h}$. The control consisted of bacteria not treated with aPDI/aBL. For

\footnotetext{
${ }^{1}$ https://aac.asm.org/
} 
the disk diffusion method, the synergistic effect was considered positive only when the differences in inhibition zones between the control and aBL/aPDI treatments were $\geq 2 \mathrm{~mm}$. In the case of the ETEST, the synergy was defined as positive only when the MIC was 2-fold lower than the MIC for the control (untreated cells).

\section{Checkerboard Assay \\ Antimicrobial blue light}

The bacterial suspension $\left(5 \times 10^{6} \mathrm{CFU} / \mathrm{ml}\right)$ was transferred with antibiotics to a 96-well plate to achieve the following concentrations in each row: $2 \times \mathrm{MIC}, \mathrm{MIC}, 1 / 2 \times \mathrm{MIC}, 1 / 4 \times \mathrm{MIC}$, and $0 \times \mathrm{MIC}$, indicating the control. Next, plates were incubated in the dark for $30 \mathrm{~min}$, followed by separate irradiation of each column of a 96-well plate with the following doses of aBL: $0 \times$ MIC, $1 / 8 \times$ MIC, $1 / 4 \times$ MIC, $1 / 2 \times$ MIC, MIC, and $2 \times$ MIC. After exposure to aBL, plates were incubated for $16 \mathrm{~h}$ at $37^{\circ} \mathrm{C}$. Next, the optical density was measured at $580 \mathrm{~nm}$ with a plate reader (Victor 1420 multilabel counter, Perkin Elmer, United States). The control group consisted of bacterial cells not treated with aBL. Each experiment was performed in three independent replicates.

\section{Antimicrobial photodynamic inactivation}

When aPDI was combined with antimicrobials, the rows of 96well plates were filled with bacterial suspension combined with antibiotics in various concentrations $(2 \times \mathrm{MIC}, \mathrm{MIC}, 1 / 2 \times \mathrm{MIC}$, $1 / 4 \times \mathrm{MIC}$, and $0 \times \mathrm{MIC})$. Additionally, the wells in columns were 2-fold diluted with $\mathrm{RB}$ to obtain final PS concentrations of $2 \times \mathrm{MIC}, \mathrm{MIC}, 1 / 2 \times \mathrm{MIC}, 1 / 4 \times \mathrm{MIC}, 1 / 8 \times \mathrm{MIC}$, and $0 \times \mathrm{MIC}$. The prepared plate was incubated for $30 \mathrm{~min}$ in the dark, and the samples were then irradiated with $515 \mathrm{~nm}$ light. The plates were then incubated at $37^{\circ} \mathrm{C}$ for $16 \mathrm{~h}$, and the optical density was measured at $580 \mathrm{~nm}$. The control group consisted of a bacterial suspension administered with RB but not treated with light.
The interaction of two tested compounds was defined based on the fractional inhibitory concentration index (FICI), which was also defined for each tested agent separately $\left(\mathrm{FIC}_{\mathrm{A}}, \mathrm{FIC}_{\mathrm{B}}\right) . \mathrm{FIC}_{\mathrm{A} / \mathrm{B}}$ is equal to the MIC value of $\mathrm{drug} \mathrm{A} / \mathrm{B}$ when used in combination divided by the MIC of drug A/B alone. The $\mathrm{FIC}_{\mathrm{I}}$ was calculated as follows: $\Sigma \mathrm{FIC}_{\mathrm{I}}=\mathrm{FIC}_{\mathrm{A}}+\mathrm{FIC}_{\mathrm{B}}$. Regarding the guidelines, the interaction between two tested factors can be defined as synergy when $\mathrm{FIC}_{\mathrm{I}}$ is $\leq 0.5$ or as antagonism when $\mathrm{FIC}_{\mathrm{I}}>4.0$ (Odds, 2003).

\section{Estimation of Posttreatment Survival Rate (CFU/ml)}

To estimate the changes in the survival rate of tested A. baumannii isolates during the checkerboard assay procedure, $10 \mu \mathrm{L}$ of each sample was transferred to PBS $30 \mathrm{~min}$ after light treatment, serially diluted, streaked on TSA plates and then incubated at $37^{\circ} \mathrm{C}$ for $16 \mathrm{~h}$. Next, the colonies were counted $(\mathrm{CFU} / \mathrm{ml})$. A synergy was confirmed when the survival rates for the combination of aBL/aPDI and antibiotic were decreased in reference to the control curve, indicating the effect of light monotherapy (aPDI/aBL).

\section{Postantibiotic Effect}

Overnight culture was diluted 1:20 (v/v) in TSB medium and then pretreated for $2 \mathrm{~h}$ with antibiotic/photosensitizer combinations as follows: (a) aPDI/aBL (MIC), (b) antibiotic $(1 / 2 \mathrm{MIC})$, and (c) aPDI/aBL (MIC) + antibiotic ( $1 / 2 \mathrm{MIC})$. Next, PS/antibiotics were removed by two PBS washing steps. Samples a and $c$ were transferred to a 24-well plate and singly irradiated with the MIC dose of aPDI/aBL. The control group of bacterial cells was not-treated with light or antimicrobial agents. Subsequently, 10- $\mu 1$ aliquot was serially diluted, streaked on TSA plates and incubated for $16 \mathrm{~h}$ at $37^{\circ} \mathrm{C}$. Samples loaded into 24-well plates were placed in an EnVision Multilabel Plate Reader (PerkinElmer, United States), and the optical density $(\lambda 600 \mathrm{~nm})$ was measured every $40 \mathrm{~min}$ for $20 \mathrm{~h}$ (30 repetitions).

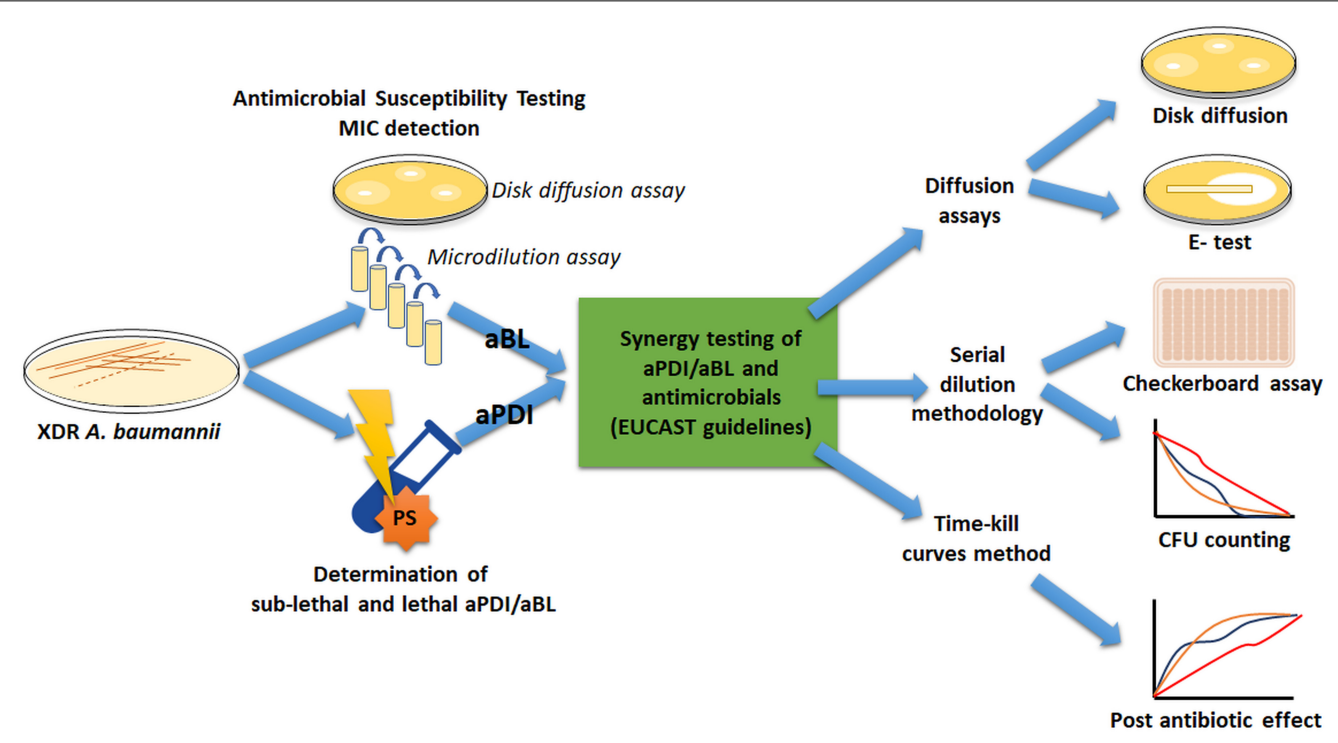

FIGURE 1 | The experimental workflow. 
Next, growth curves of bacterial cells exposed to combined treatments were compared to those of the control as well as to curves representing monotreatments (MIC aPDI/aBL, 1/2 MIC antibiotic). The presence of PAE (time of delayed bacterial recovery during the growth vs. time curves) indicated a possible synergistic effect. The PAE can be calculated with the following formula: $(\Delta \mathrm{t}) P A E=T-C$, where $T$ is the time the bacterial population requires to reach half the maximum optical density after the tested compound (e.g., antibiotic) is removed and $C$ is the time required for untreated cells to reach half of the maximum absorbance (Odenholt, 2001). A synergistic effect was considered significant when the PAE parameter $\Delta t \geq 3 \mathrm{~h}$ and partial when $1.5 \mathrm{~h} \leq \Delta t>2.9 \mathrm{~h}$. Colony counting was necessary to establish the viable cell number in tested samples and controls.

\section{ROS Detection}

Reactive oxygen species detection was performed using $3^{\prime}$-(p-aminophenyl) fluorescein (APF, Thermo Fisher Scientific, United States), which is a fluorescent indicator of hydroxyl radicals $\left({ }^{\bullet} \mathrm{OH}\right)$. In addition, APF may also be used to detect exclusively singlet oxygen when administered with DMSO $(0.1 \%)$. The protocol described by Price et al. allows the quenching of the fluorescence linked to the hydroxyl radicals (Price et al., 2009). Thus, the detection of ROS was carried out both in the absence and presence of $0.1 \%$ DMSO for combined aBL/aPDI treatment, monotreatments (aPDI/aBL) and untreated, control samples. The concentrations of APF, CST, and DOX were $10 \mu \mathrm{g} / \mathrm{ml}, 2 \mu \mathrm{g} / \mathrm{ml}$, and $32 \mu \mathrm{g} / \mathrm{ml}$, respectively. $\mathrm{RB}$ was used at a concentration of $5 \mu \mathrm{M}$. Combined samples were prepared in PBS in black 96-well plates and then incubated for $15 \mathrm{~min}$ in the dark at room temperature. Next, a $515 \mathrm{~nm}$ light dose of $90 \mathrm{~J} / \mathrm{cm}^{2}$ was delivered. In the case of $\mathrm{aBL}$, samples were exposed to a $411 \mathrm{~nm}$ light dose of $90.1 \mathrm{~J} / \mathrm{cm}^{2}$. Fluorescence measurements were performed immediately after aPDI/aBL irradiation with an EnVision Multilabel Plate Reader (PerkinElmer, United States) at emission/excitation wavelengths of $490 / 515 \mathrm{~nm}$.

\section{RESULTS}

\section{Experimental Workflow}

To meet the international standards for synergy testing, numerous official AST procedures were employed to ensure that reliable conclusions were drawn; thus, we introduce a general workflow diagram to facilitate following the obtained results (Figure 1).

Two XDR A. baumannii isolates (nos. 127 and 128) were employed. The first stage was to characterize the drug resistance profile of A. baumannii isolates, followed by antimicrobial MIC evaluation. Next, overnight bacterial cultures were treated with different light doses and/or PS (i.e., RB) concentrations to determine both lethal and sublethal photo treatment conditions. The identification of sublethal doses was required because adequate synergy testing needs to be performed with living cells. Afterward, combined sublethal aPDI/aBL and sub-MIC doses of antimicrobials were investigated to find possible synergies.
For proper implementation of synergy testing, various standard methodologies were used.

\section{Identification of Lethal and Sublethal Treatments}

Adequate synergy testing required the preliminary characteristics of the studied A. baumannii isolates regarding their drug resistance profiles as well as their response to aPDI and aBL treatments. Detailed characteristics are presented in Table $\mathbf{1}$.
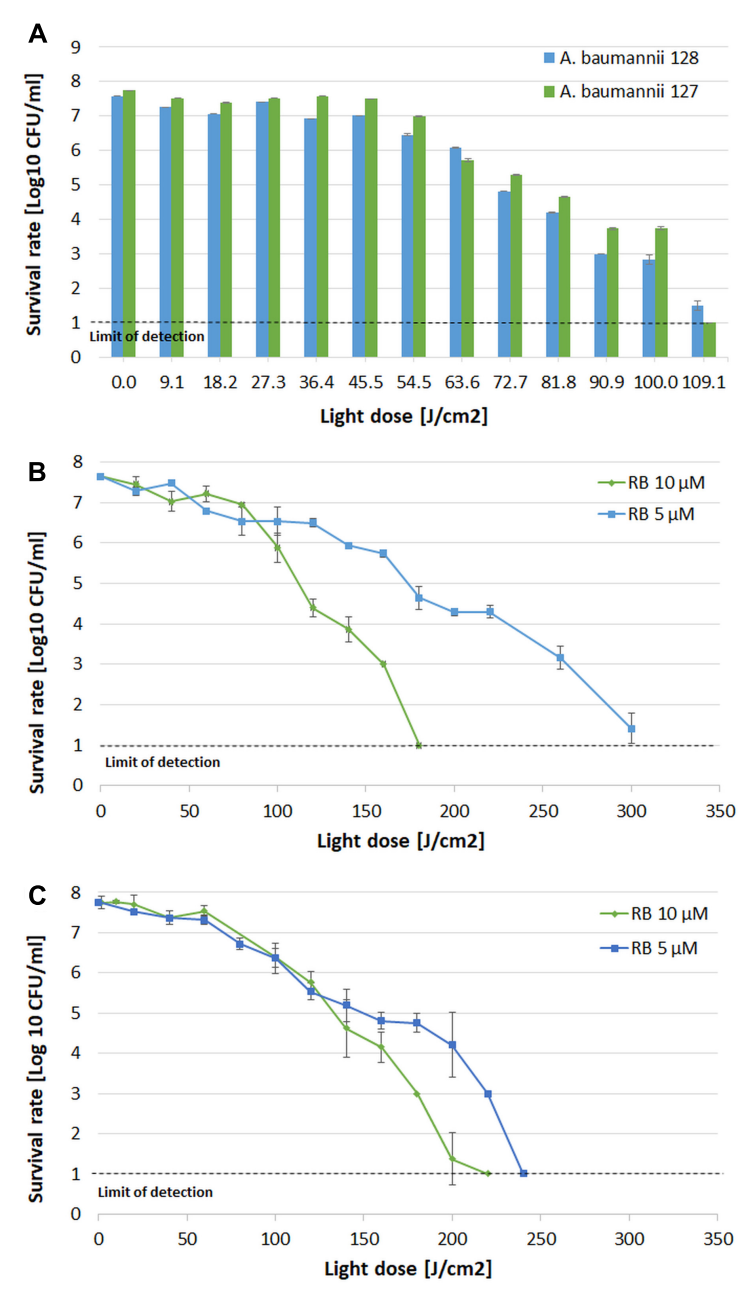

FIGURE 2 | Influence of aBL and aPDI on A. baumannii strains. (A) aBL treatment of $A$. baumannii isolates. Light doses ranging from 9.1 to 109.1 $\mathrm{J} / \mathrm{cm}^{2}$ (irradiance $130 \mathrm{~mW} / \mathrm{cm}^{2}$, irradiation time from 79 to $952 \mathrm{~s}, \lambda 411 \mathrm{~nm}$ ) were applied to two XDR strains (blue bars - strain no. 128; green bars strain no. 127. (B) aPDI treatment of $A$. baumannii strain no. 128. Light doses ranging from 20 to $300 \mathrm{~J} / \mathrm{cm}^{2}$ (irradiance $70 \mathrm{~mW} / \mathrm{cm}^{2}$, irradiation time from 303 to $4545 \mathrm{~s}, \lambda 515 \mathrm{~nm}$ ) and two rose bengal concentrations were tested (green diamonds - $10 \mu \mathrm{M}$; blue squares $-5 \mu \mathrm{M}$ ). (C) aPDI treatment of A. baumannii strain no. 127. Light doses ranging from 20 to $240 \mathrm{~J} / \mathrm{cm}^{2}$ (irradiance $70 \mathrm{~mW} / \mathrm{cm}^{2}$, irradiation time from 303 to $3636 \mathrm{~s} ; \lambda 515 \mathrm{~nm}$ ) and two rose bengal concentrations were tested (green diamonds - $10 \mu \mathrm{M}$; blue squares $-5 \mu \mathrm{M})$. The detection limit was $10 \mathrm{CFU} / \mathrm{ml}$. The values are the means of three separate experiments. Values were combined by a line for better visualization of the data. 
TABLE 2 | Sublethal aPDI impacts on A. baumannii drug susceptibility.

\begin{tabular}{|c|c|c|c|c|c|c|c|c|c|c|c|c|c|}
\hline \multicolumn{14}{|c|}{ aPDI ( $\lambda 515 \mathrm{~nm})$} \\
\hline & \multirow[t]{2}{*}{ Antibiotic } & \multicolumn{2}{|c|}{ Control } & \multicolumn{2}{|c|}{$\begin{array}{l}\text { Light }\left(5 \mathrm{~J} / \mathrm{cm}^{2}\right) \\
+\mathrm{RB}(10 \mu \mathrm{M})\end{array}$} & \multicolumn{2}{|c|}{$\begin{array}{l}\text { Light }\left(10 \mathrm{~J} / \mathrm{cm}^{2}\right) \\
+\mathrm{RB}(10 \mu \mathrm{M})\end{array}$} & \multicolumn{2}{|c|}{ 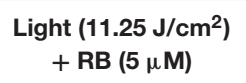 } & \multicolumn{2}{|c|}{$\begin{array}{l}\text { Light (18.0 J/cm²) } \\
+ \text { RB }(5 \mu \mathrm{M})\end{array}$} & \multicolumn{2}{|c|}{$\begin{array}{c}\text { Light }\left(22.5 \mathrm{~J} / \mathrm{cm}^{2}\right) \\
+ \text { RB }(5 \mu \mathrm{M})\end{array}$} \\
\hline & & $\begin{array}{c}\text { Disk } \\
\text { diffusion } \\
\text { [mm] }\end{array}$ & $\begin{array}{c}E \text {-test } \\
{[\mu \mathrm{g} / \mathrm{ml}]}\end{array}$ & $\begin{array}{c}\text { Disk } \\
\text { diffusion } \\
\text { [mm] }\end{array}$ & $\begin{array}{c}E \text {-test } \\
{[\mu \mathrm{g} / \mathrm{ml}]}\end{array}$ & $\begin{array}{c}\text { Disk } \\
\text { diffusion } \\
{[\mathrm{mm}]}\end{array}$ & $\begin{array}{c}\text { E-test } \\
{[\mu \mathrm{g} / \mathrm{ml}]}\end{array}$ & $\begin{array}{c}\text { Disk } \\
\text { diffusion } \\
\text { [mm] }\end{array}$ & $\begin{array}{c}\text { E-test } \\
{[\mu \mathrm{g} / \mathrm{ml}]}\end{array}$ & $\begin{array}{c}\text { Disk } \\
\text { diffusion } \\
\text { [mm] }\end{array}$ & $\begin{array}{c}E \text {-test } \\
{[\mu \mathrm{g} / \mathrm{ml}]}\end{array}$ & $\begin{array}{c}\text { Disk } \\
\text { diffusion } \\
\text { [mm] }\end{array}$ & $\begin{array}{c}E \text {-test } \\
{[\mu \mathrm{g} / \mathrm{ml}]}\end{array}$ \\
\hline \multirow[t]{10}{*}{ A. baumannii 127} & GEN & $6(\mathrm{R})$ & $\geq 256(\mathrm{R})$ & $6(\mathrm{R})$ & $\geq 256(\mathrm{R})$ & $6(\mathrm{R})$ & $\geq 256(\mathrm{R})$ & $6(\mathrm{R})$ & $\geq 256(\mathrm{R})$ & $6(\mathrm{R})$ & $\geq 256(\mathrm{R})$ & $6(\mathrm{R})$ & $24(\mathrm{R})$ \\
\hline & $\mathrm{DOX}(\mathrm{NR})$ & 6 & 128 & 6 & 128 & 7.4 & 128 & 7.3 & 32 & 9.1 & 32 & 10.4 & 6 \\
\hline & SXT & $6(\mathrm{R})$ & $\geq 32(\mathrm{R})$ & $6(\mathrm{R})$ & $\geq 32(\mathrm{R})$ & $6(\mathrm{R})$ & $\geq 32(\mathrm{R})$ & $6(\mathrm{R})$ & $\geq 32(\mathrm{R})$ & $6(\mathrm{R})$ & $\geq 32(\mathrm{R})$ & $6(\mathrm{R})$ & $\geq 32(\mathrm{R})$ \\
\hline & CIP & $6(\mathrm{R})$ & $\geq 32(R)$ & $6(\mathrm{R})$ & $\geq 32(R)$ & $6(\mathrm{R})$ & $\geq 32(R)$ & $6(\mathrm{R})$ & $\geq 32(R)$ & $6(\mathrm{R})$ & $\geq 32(\mathrm{R})$ & $6(\mathrm{R})$ & $\geq 32(\mathrm{R})$ \\
\hline & IPM & $6.8(\mathrm{R})$ & $\geq 32(\mathrm{R})$ & $7.9(\mathrm{R})$ & $24(\mathrm{R})$ & $10(\mathrm{R})$ & $\geq 32(\mathrm{R})$ & $10.2(\mathrm{R})$ & $\geq 32(\mathrm{R})$ & $11.6(\mathrm{R})$ & $12(\mathrm{R})$ & $12.2(\mathrm{R})$ & $8(R)$ \\
\hline & TZP & 6 & $\geq 256$ & 6 & $\geq 256$ & 6 & $\geq 256$ & 6.9 & $\geq 256$ & 8.4 & $\geq 256$ & 6.7 & $\geq 256$ \\
\hline & CAZ (NR) & 6 & $\geq 256$ & 6 & $\geq 256$ & 6 & $\geq 256$ & 6 & $\geq 256$ & 6 & $\geq 256$ & 6 & $\geq 256$ \\
\hline & SAM & 6.5 & 48 & 7.1 & 24 & 7.7 & 32 & 9.7 & 32 & 10.0 & 12 & 11.2 & 12 \\
\hline & CST & 14.0 & $0.094(\mathrm{~S})$ & 14.6 & $0.125(\mathrm{~S})$ & 14.3 & $0.125(S)$ & 13.9 & $0.125(\mathrm{~S})$ & 16.7 & $0.125(\mathrm{~S})$ & 18.3 & $0.094(\mathrm{~S})$ \\
\hline & Antibiotic & \multicolumn{2}{|c|}{ Control } & \multicolumn{2}{|c|}{$\begin{array}{l}\text { Light }\left(5 \mathrm{~J} / \mathrm{cm}^{2}\right) \\
+\mathrm{RB}(10 \mu \mathrm{M})\end{array}$} & \multicolumn{2}{|c|}{$\begin{array}{l}\text { Light }\left(10 \mathrm{~J} / \mathrm{cm}^{2}\right) \\
+\mathrm{RB}(10 \mu \mathrm{M})\end{array}$} & \multicolumn{2}{|c|}{ 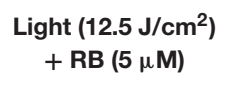 } & \multicolumn{2}{|c|}{$\begin{array}{c}\text { Light }\left(20.0 \mathrm{~J} / \mathrm{cm}^{2}\right) \\
+ \text { RB }(5 \mu \mathrm{M})\end{array}$} & \multicolumn{2}{|c|}{$\begin{array}{c}\text { Light }\left(22.5 \mathrm{~J} / \mathrm{cm}^{2}\right) \\
+\mathrm{RB}(5 \mu \mathrm{M})\end{array}$} \\
\hline \multirow[t]{9}{*}{ A. baumannii 128} & GEN & $6(\mathrm{R})$ & $\geq 256(R)$ & $6(\mathrm{R})$ & $\geq 256(\mathrm{R})$ & $6(\mathrm{R})$ & $\geq 256$ & $6(\mathrm{R})$ & $\geq 256(R)$ & $6(\mathrm{R})$ & $128(\mathrm{R})$ & $6(\mathrm{R})$ & $64(\mathrm{R})$ \\
\hline & $\mathrm{DOX}(\mathrm{NR})$ & 6.6 & 48 & 6.2 & 24 & 7.1 & 12 & 7.8 & 24 & 9.1 & 8 & 11.6 & 6 \\
\hline & SXT & $6(\mathrm{R})$ & $\geq 32(\mathrm{R})$ & $6(\mathrm{R})$ & $\geq 32(\mathrm{R})$ & $6(\mathrm{R})$ & $\geq 32(\mathrm{R})$ & $6(\mathrm{R})$ & $\geq 32(R)$ & $6(\mathrm{R})$ & $\geq 32(\mathrm{R})$ & $6(\mathrm{R})$ & $\geq 32(\mathrm{R})$ \\
\hline & $\mathrm{CIP}$ & $6(\mathrm{R})$ & $\geq 32(\mathrm{R})$ & $6(\mathrm{R})$ & $\geq 32(\mathrm{R})$ & $6(\mathrm{R})$ & $\geq 32$ & $6(\mathrm{R})$ & $\geq 32(\mathrm{R})$ & $6.1(\mathrm{R})$ & $12(\mathrm{R})$ & $6(\mathrm{R})$ & $32(\mathrm{R})$ \\
\hline & IPM & $7.3(\mathrm{R})$ & $\geq 32(\mathrm{R})$ & $8.3(R)$ & $\geq 32(\mathrm{R})$ & $8.2(R)$ & 12 & $8.9(\mathrm{R})$ & $\geq 32(\mathrm{R})$ & $9.8(R)$ & $8(\mathrm{~S} / \mathrm{R})$ & $14(\mathrm{R})$ & $2(\mathrm{~S})$ \\
\hline & TZP & 6 & $\geq 256$ & 6 & $\geq 256$ & 6 & $\geq 256$ & 6 & $\geq 256$ & 6.1 & $\geq 256$ & 10.0 & $\geq 256$ \\
\hline & $\mathrm{CAZ}(\mathrm{NR})$ & 6 & $\geq 256$ & 6 & $\geq 256$ & 6 & $\geq 256$ & 6 & $\geq 256$ & 6 & $\geq 256$ & 6 & 64 \\
\hline & SAM & 8.0 & 48 & 9.2 & 44 & 7.4 & 16 & 8.8 & 32 & 9.1 & 24 & 14.8 & 12 \\
\hline & CST & 13.7 & $0.094(\mathrm{~S})$ & 15 & $0.19(\mathrm{~S})$ & 13.6 & $0.094(\mathrm{~S})$ & 14.1 & $0.094(\mathrm{~S})$ & 15.9 & $0.094(\mathrm{~S})$ & 16.9 & $0.094(\mathrm{~S})$ \\
\hline
\end{tabular}

NR, not recommended; $R$, resistant; S, susceptible; CAZ, ceftazidime; CIP, ciprofloxacin; CST, colistin; DOX, doxycycline; GEN, gentamycin; IPM, imipenem; SAM, ampicillin-sulbactam; SXT, trimethoprim-sulfamethoxazole; TZP, piperacillin-tazobactam.

The results indicated that both endogenously- $(\mathrm{aBL})$ and exogenously administered PS (aPDI)-based phototreatments could reach high bactericidal efficacy, leading to a reduction in cell viability by $\geq 6 \log _{10}$ units (Figure 2 ).

In the case of aBL (Figure 2A), the sublethal light dose was defined as $63.6 \mathrm{~J} / \mathrm{cm}^{2}$, which reduced bacterial viability by 1.5 and $2 \log _{10}$ (in the cases of A. baumannii no. 128 and 127, respectively). When considering aPDI treatment with two studied $\mathrm{RB}$ concentrations vs. light doses, different combinations could define sublethal conditions (Figures $2 \mathbf{B}, \mathbf{C}$ ). In the case of $5 \mu \mathrm{M}$ $\mathrm{RB}$, the sublethal aPDI could be defined as 160 and $100 \mathrm{~J} / \mathrm{cm}^{2}$, resulting in cell viability reduction by 1.9 and $1.4 \log _{10}$ units (in the cases of A. baumannii no. 128 and no. 127, respectively). When $10 \mu \mathrm{M}$ RB was used, the sublethal light dose was defined as 100 and $120 \mathrm{~J} / \mathrm{cm}^{2}$, which led to viable cell reduction by 1.7 and 2 $\log _{10}$ units (for A. baumannii no. 128 and 127, respectively).

\section{Diffusion Based Assays for Synergy Testing}

First-line screening for potent synergies of antimicrobials was performed by employing diffusion-based techniques. The results indicated that in the case of both photobased treatments, the employment of sublethal aBL/aPDI conditions influenced A. baumannii susceptibility to numerous routinely used antimicrobials, resulting in larger growth inhibition zones (in the case of the disk-diffusion assay) and decreased MICs (for the ETEST) (Tables 2, 3). Though the impact of aPDI on A. baumannii drug susceptibility was observed in the cases of numerous antimicrobial agents (i.e., gentamycin, doxycycline, imipenem, ampicillin/sulbactam, and colistin), the most pronounced effect was reported for gentamycin; in this case, sublethal aPDI treatment reduced the MIC values 42 -fold for A. baumannii no. 127 isolate from $1024 \mu \mathrm{g} / \mathrm{ml}$ (as stated in Table 1) to $24 \mu \mathrm{g} / \mathrm{ml}$. Similar results were reported for aBL treatment (Table 3). Sublethal aBL levels resulted in larger growth inhibition zones for the A. baumannii no. 128 isolate (i.e., from 7.3 to $8.1 \mathrm{~mm}$ and from 13.7 to $14.2 \mathrm{~mm}$, in the cases of imipenem and colistin, respectively) and in case of A. baumannii no. 127 decreased MICs (i.e., reduction in MIC from 128 to $64 \mu \mathrm{g} / \mathrm{ml}$ and from 48 to $32 \mu \mathrm{g} / \mathrm{ml}$ in the cases of doxycycline and ampicillin/sulbactam, respectively) (Table 3).

\section{Serial Dilution Methodology for Synergy Testing}

To further confirm and/or detect other synergies, the serial dilution methodology was employed. Figure 3 exemplifies the checkerboard assay. The obtained results indicate that with the employment of phototreatment/antimicrobial combinations, 
TABLE 3 | Sublethal and lethal aBL impact on A. baumannii drug susceptibility.

\begin{tabular}{|c|c|c|c|c|c|c|c|c|c|c|}
\hline \multicolumn{11}{|c|}{ aBL $(\lambda 411 \mathrm{~nm})$} \\
\hline & \multirow[t]{2}{*}{ Antibiotic } & \multicolumn{2}{|c|}{ Control } & \multirow{2}{*}{$\begin{array}{c}36.4 \mathrm{~J} / \mathrm{cm}^{2} \\
\text { Disk } \\
\text { diffusion } \\
{[\mathrm{mm}]}\end{array}$} & \multirow{2}{*}{$\begin{array}{c}54.5 \mathrm{~J} / \mathrm{cm}^{2} \\
\text { Disk } \\
\text { diffusion } \\
{[\mathrm{mm}]}\end{array}$} & \multirow{2}{*}{$\begin{array}{c}72.7 \mathrm{~J} / \mathrm{cm}^{2} \\
\text { Disk } \\
\text { diffusion } \\
{[\mathrm{mm}]}\end{array}$} & \multicolumn{2}{|c|}{$90.9 \mathrm{~J} / \mathrm{cm}^{2}$} & \multicolumn{2}{|c|}{$109.1 \mathrm{~J} / \mathrm{cm}^{2}$} \\
\hline & & $\begin{array}{c}\text { Disk } \\
\text { diffusion } \\
\text { [mm] }\end{array}$ & $\begin{array}{c}E \text {-test } \\
{[\mu \mathrm{g} / \mathrm{ml}]}\end{array}$ & & & & $\begin{array}{c}\text { Disk } \\
\text { diffusion } \\
\text { [mm] }\end{array}$ & $\begin{array}{c}E \text {-test } \\
{[\mu \mathrm{g} / \mathrm{ml}]}\end{array}$ & $\begin{array}{c}\text { Disk } \\
\text { diffusion } \\
\text { [mm] }\end{array}$ & $\begin{array}{c}\text { E-test } \\
{[\mu \mathrm{g} / \mathrm{ml}]}\end{array}$ \\
\hline \multirow[t]{9}{*}{ A. baumannii 127} & GEN & $6(\mathrm{R})$ & $\geq 256(R)$ & $6(\mathrm{R})$ & $6(\mathrm{R})$ & $6(\mathrm{R})$ & $6(\mathrm{R})$ & $\geq 256(R)$ & $6(\mathrm{R})$ & $\geq 256(\mathrm{R})$ \\
\hline & $\mathrm{DOX}(\mathrm{NR})$ & 6 & 128 & 6.5 & 6 & 6 & 6 & 64 & 6 & 48 \\
\hline & SXT & $6(\mathrm{R})$ & $\geq 32(\mathrm{R})$ & $6(\mathrm{R})$ & $6(\mathrm{R})$ & $6(\mathrm{R})$ & $6(\mathrm{R})$ & $\geq 32(\mathrm{R})$ & $6(\mathrm{R})$ & $\geq 32(\mathrm{R})$ \\
\hline & $\mathrm{CIP}$ & $6(\mathrm{R})$ & $\geq 32(\mathrm{R})$ & $6(\mathrm{R})$ & $6(\mathrm{R})$ & $6(\mathrm{R})$ & $6(\mathrm{R})$ & $\geq 32(\mathrm{R})$ & $6(\mathrm{R})$ & $\geq 32(\mathrm{R})$ \\
\hline & IPM & $6.8(\mathrm{R})$ & $\geq 32(R)$ & 8.2 & 8.0 & 7.6 & 7.7 & $\geq 32$ & $8.6(\mathrm{R})$ & $\geq 32(\mathrm{R})$ \\
\hline & TZP & 6 & $\geq 256$ & 6 & 6 & 6 & 6 & $\geq 256$ & 6 & $\geq 256$ \\
\hline & CAZ (NR) & 6 & $\geq 256$ & 6 & 6 & 6 & 6 & $\geq 256$ & 6 & $\geq 256$ \\
\hline & SAM & 6.5 & 48 & 7.8 & 7.3 & 7.5 & 8.1 & 32 & 6 & 24 \\
\hline & CST & 14.0 & $0.094(\mathrm{~S})$ & 14.0 & 14.3 & 14.1 & 15.4 & $0.125(\mathrm{~S})$ & 16 & $0.125(\mathrm{~S})$ \\
\hline \multirow[t]{9}{*}{ A. baumannii 128} & GEN & \multicolumn{2}{|c|}{$6(\mathrm{R})$} & $\geq 256(R)$ & $6(\mathrm{R})$ & $6(\mathrm{R})$ & \multicolumn{2}{|c|}{$6(\mathrm{R})$} & \multicolumn{2}{|c|}{$6(\mathrm{R})$} \\
\hline & DOX (NR) & 6.6 & 48 & 6.1 & 7.8 & 7.8 & 7.1 & $256(R)$ & $6(\mathrm{R})$ & $256(R)$ \\
\hline & SXT & $6(\mathrm{R})$ & $\geq 32(R)$ & $6(\mathrm{R})$ & $6(\mathrm{R})$ & $6(\mathrm{R})$ & $6(\mathrm{R})$ & $\geq 32$ & 7.2 & 16 \\
\hline & $\mathrm{CIP}$ & $6(\mathrm{R})$ & $\geq 32(R)$ & $6(\mathrm{R})$ & $6(\mathrm{R})$ & 6 & 6 & $\geq 32(R)$ & $6(\mathrm{R})$ & $\geq 32(\mathrm{R})$ \\
\hline & IPM & $7.3(\mathrm{R})$ & $\geq 32(R)$ & $7.8(\mathrm{R})$ & $8.1(\mathrm{R})$ & $8.2(\mathrm{R})$ & $8.8(\mathrm{R})$ & $\geq 32$ & $6(\mathrm{R})$ & $\geq 32(\mathrm{R})$ \\
\hline & TZP & 6 & $\geq 256$ & 6 & 6 & 6 & 6 & $\geq 32(\mathrm{R})$ & $9.1(\mathrm{R})$ & $\geq 32(\mathrm{R})$ \\
\hline & CAZ (NR) & 6 & $\geq 256$ & 6 & 6 & 6 & 6 & $\geq 256$ & 6 & $\geq 256$ \\
\hline & SAM & 8.0 & 48 & 7.6 & 7.2 & 7.5 & 7.2 & $\geq 256$ & 6 & $\geq 256$ \\
\hline & CST & 13.7 & $0.094(\mathrm{~S})$ & 13.8 & 14.2 & 14.7 & 13.9 & 48 & 8.9 & 32 \\
\hline
\end{tabular}

NR, not recommended; $R$, resistant; S, susceptible; CAZ, ceftazidime; CIP, ciprofloxacin; CST, colistin; DOX, doxycycline; GEN, gentamycin; IPM, imipenem; SAM, ampicillin-sulbactam; SXT, trimethoprim-sulfamethoxazole; TZP, piperacillin-tazobactam.

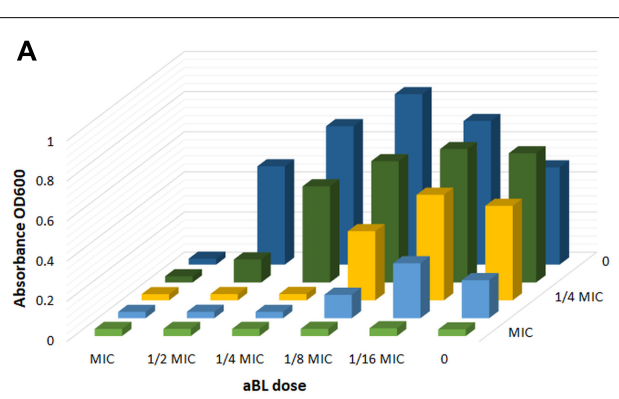

C

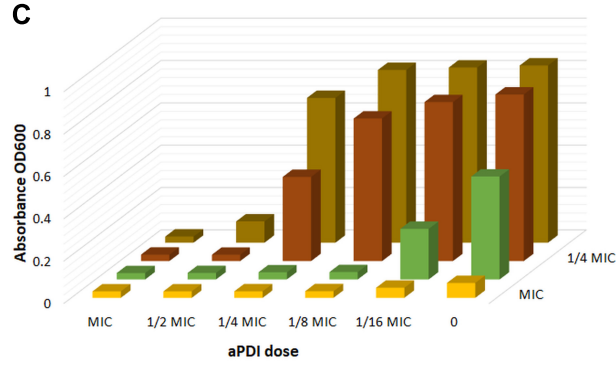

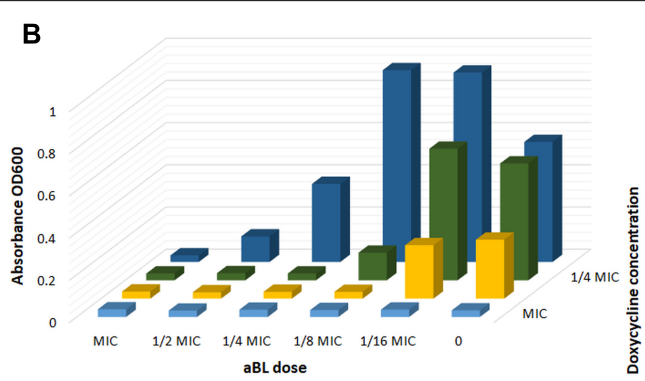

D

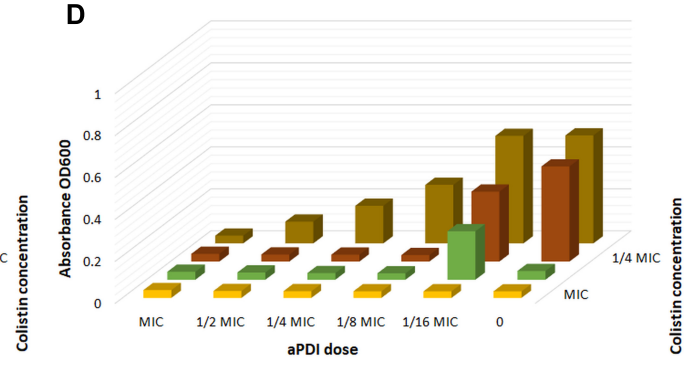

FIGURE 3 | Checkerboard analysis. (A) Checkerboard analysis of aBL/doxycycline combined treatment for A. baumannii no. 128. (B) Checkerboard analysis of aBL/doxycycline treatment for $A$. baumannii no. 127. (C) Checkerboard analysis of aPDI/colistin combined treatment for A. baumannii no. 128. (D) Checkerboard analysis of aPDI/colistin treatment for A. baumannii no. 127.

successful A. baumannii eradication was achieved with the use of as little as $1 / 4$ of the MIC of doxycycline and colistin together with $1 / 4$ of the MIC of aBL and $1 / 8$ of the MIC of aPDI (Figure 3 ).
Checkerboard FIC calculations confirmed the existence of synergistic interactions when phototreatment was used in combination with doxycycline, imipenem or colistin; 
TABLE 4 | Checkerboard FIC calculation.

\begin{tabular}{lcclcc}
\hline Antibiotic & \multicolumn{2}{c}{$\boldsymbol{A}$. baumannii } & $\mathbf{1 2 7}$ & & \multicolumn{2}{c}{$\boldsymbol{A}$. baumannii $\mathbf{1 2 8}$} \\
\cline { 2 - 3 } \cline { 6 - 6 } & aBL & aPDI & & aBL & aPDI \\
\hline GEN & $>0.5^{\mathrm{a}}$ & $>0.5$ & & $>0.5$ & $>0.5$ \\
DOX & $\mathbf{0 . 3 7 5}$ & $>0.5$ & & $\mathbf{0 . 5}$ & $\mathbf{0 . 3 7 5}$ \\
SXT & $\mathbf{0 . 5}$ & $>0.5$ & & $>0.5$ & $>0.5$ \\
CIP & $>0.5$ & $>0.5$ & & $>0.5$ & $>0.5$ \\
IPM & $>0.5$ & $>0.5$ & & $>0.5$ & $\mathbf{0 . 3 7 5}$ \\
TZP & $>0.5$ & $>0.5$ & & $>0.5$ & $>0.5$ \\
CAZ & $>0.5$ & $>0.5$ & & $>0.5$ & $>0.5$ \\
SAM & $>0.5$ & $>0.5$ & & $>0.5$ & $>0.5$ \\
CST & $>0.5$ & $\mathbf{0 . 3 7 5}$ & $>0.5$ & $\mathbf{0 . 3 7 5}$
\end{tabular}

Bold indicates possible synergistic interactions. ${ }^{a} \mathrm{FICl}$ index; $\mathrm{FICl}=\mathrm{FIC} \mathrm{a}+\mathrm{FIC}$ CAZ, ceftazidime; CIP, ciprofloxacin; CST, colistin; DOX, doxycycline; GEN, gentamycin; IPM, imipenem; SAM, ampicillin-sulbactam; SXT, trimethoprimsulfamethoxazole; TZP, piperacillin-tazobactam.

furthermore, the results indicated a synergy between aBL and trimethoprim/sulfamethoxazole treatments (Table 4).

Along with checkerboard analysis, direct post-treatment probing and $\mathrm{CFU}$ counting were performed. The obtained results are exemplified by aBL/doxycycline and aPDI/colistin combinations (Figure 4). The obtained results clearly indicate that combined treatment led to more effective bacterial killing of both A. baumannii isolates with the employment of decreased antibiotic concentrations as well as lower aBL/aPDI doses (Figure 4). For all other combinations, the obtained results are summarized in Table 6, where all data from synergy testing via all included assays are shown. If characteristic "shifting" of bacterial survival rate curves was reported, the combination was marked with a "+" to indicate possible synergistic interaction.

\section{Time-Kill Curves for Synergy Testing}

Finally, possible synergies were confirmed and newly detected with PAE testing. The characteristic "shifting" of growth curves of A. baumannii pre-exposed with a combined treatment indicates that this approach delayed bacterial recovery (Figure 5). Figure 5 only show the results for aBL/doxycycline and aPDI/colistin combinations. In the case of A. baumannii no. 127, it is clear that only combined aBL/DOX and aPDI/CST treatment leads to delayed bacterial recovery resulting in PAEs of approximately 330 and $210 \mathrm{~min}$, respectively (Figures 5B,D). In the case of A. baumannii no. 128 , a clear indication of synergy was observed only for the aBL/DOX combination (Figure 5A); however, only a limited PAE was found for the aPDI and CST combined treatment (Figure 5C). This case exemplifies ambiguous results, which were marked " $+/-$ " in the summary tables (Tables 5, 6). For all other combinations, the results are summarized in Tables 5, 6. If characteristic "shifting" of bacterial growth curves was reported, the combination was marked with "+" to indicate a possible synergistic interaction.

The most pronounced indication concerned a aBL/aPDI and DOX combined treatment (Table 5). Clear "shifting" and a significant $\Delta t$ (PAE) were observed for exposure to the combination of DOX and either aBL or aPDI. The same result was reported in the case of aBL/SAM and aBL/IPM combinations. Other inconclusive results were found for $\mathrm{aBL}$ treatment combined with GEN, SXT or CIP. In these cases, the

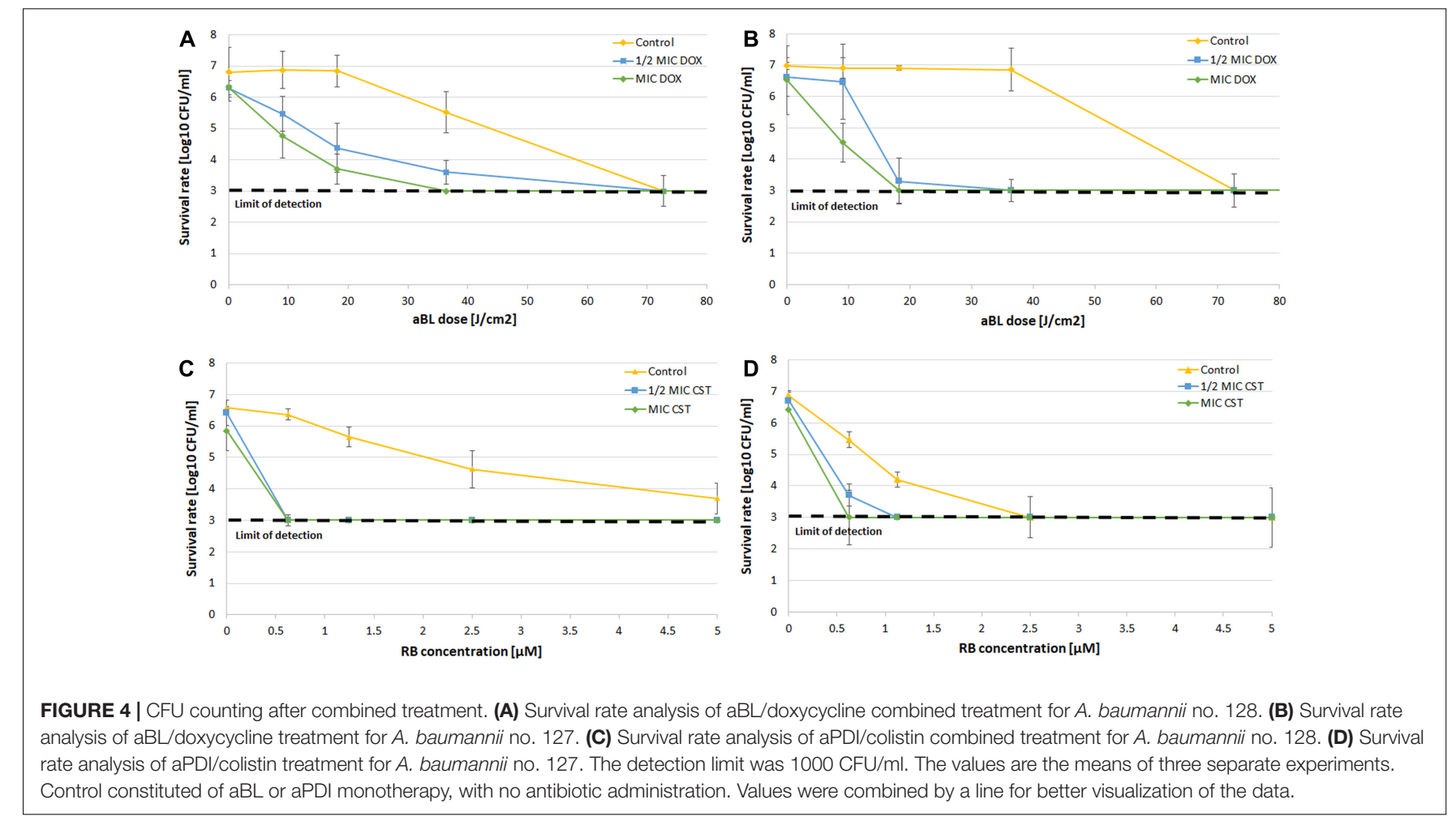



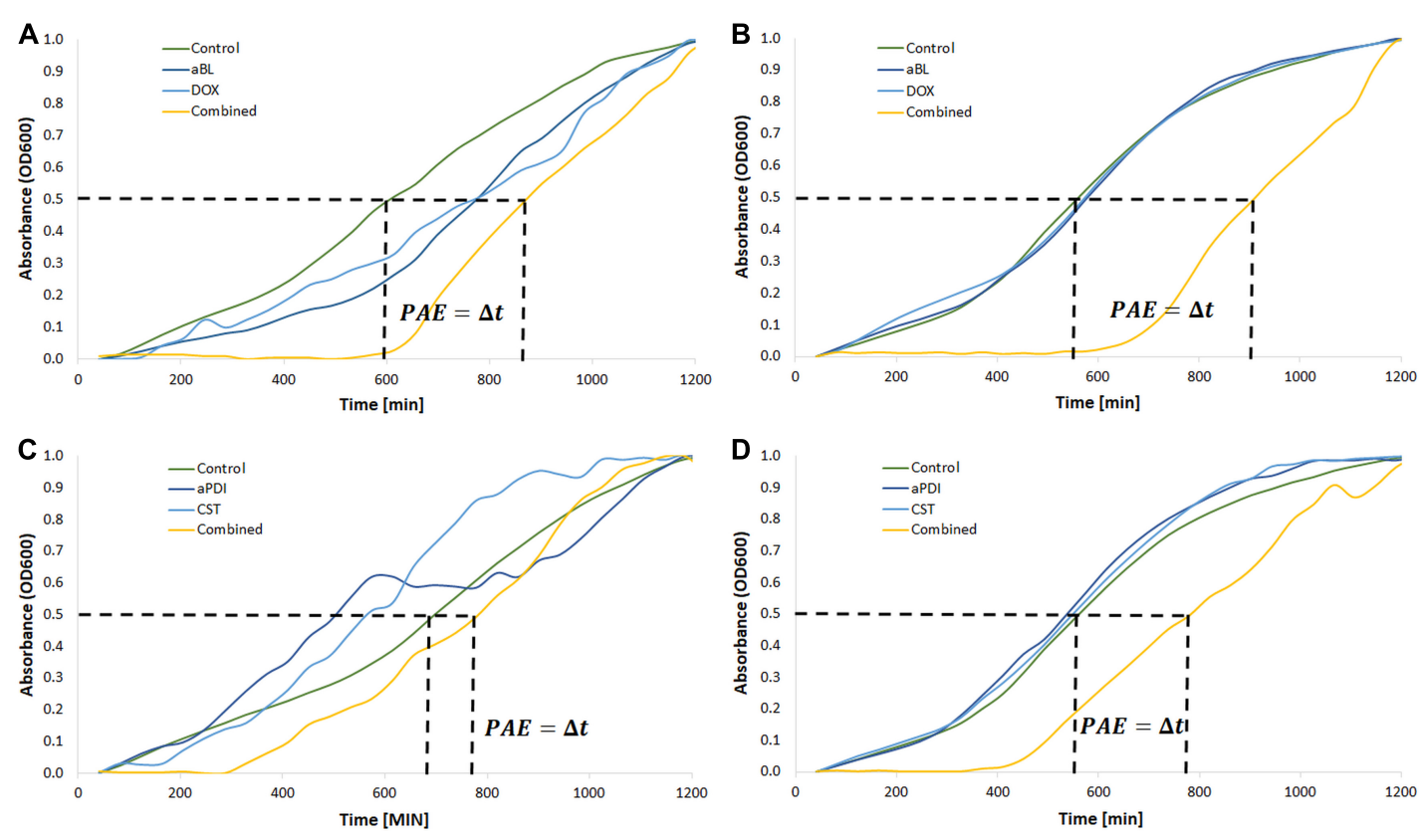

FIGURE 5 | Postantibiotic effect testing. (A) Growth curve analysis of aBL/doxycycline combined treatment for A. baumannii no. 128. (B) Growth curve analysis of aBL/doxycycline treatment for A. baumannii no. 127. (C) Growth curve analysis of aPDI/colistin combined treatment for $A$. baumannii no. 128. (D) Growth curve analysis of aPDI/colistin treatment for A. baumannii no. 127. Phototreatments (aBL and aPDI) were employed with MIC doses. Antibiotics (doxycycline, DOX; colistin CST) were administered at $1 / 2$ MIC. Only one representative curve was presented.

indisputable results were observed for only one of two studied A. baumannii isolates. The same was observed for the aPDI and SXT combination. Significant strain dependence was reported for aBL/CST, aPDI/GEN and aPDI/CST combined treatments.

\section{Possible aBL/aPDI and Antimicrobials Synergies}

All data collected within the current study are summarized in Table 6 to provide better insight into the possible synergies

TABLE 5 | Postantibiotic effect on A. baumannii clinical isolates.

\begin{tabular}{|c|c|c|c|c|}
\hline \multirow[t]{2}{*}{ Antibiotic } & \multicolumn{2}{|c|}{ A. baumannii 127} & \multicolumn{2}{|c|}{ A. baumannii 128} \\
\hline & $\mathrm{aBL}$ & aPDI & $\mathrm{aBL}$ & aPDI \\
\hline GEN & + & + & $+1-$ & - \\
\hline DOX & + & + & + & + \\
\hline SXT & + & + & $+1-$ & $+/-$ \\
\hline CIP & + & - & $+/-$ & $+/-$ \\
\hline IPM & + & - & + & $+/-$ \\
\hline TZP & - & $+/-$ & - & - \\
\hline CAZ & - & $+/-$ & - & - \\
\hline SAM & + & $+/-$ & + & - \\
\hline CST & - & + & + & - \\
\hline
\end{tabular}

(+) synergistic effect; (+/-) partial synergy; (-) no synergistic effect. CAZ, ceftazidime; CIP, ciprofloxacin; CST, colistin; DOX, doxycycline; GEN, gentamycin; IPM, imipenem; SAM, ampicillin-sulbactam; SXT, trimethoprim-sulfamethoxazole; TZP, piperacillin-tazobactam.
(Table 6). The most potent strain-independent synergies are marked with gray.

Some antimicrobials (i.e., DOX) interact synergistically with both aBL and aPDI treatments, and other interactions were observed when endogenously produced or exogenously administered PSs were involved in photodynamic inactivation (i.e., IPM and SAM with aBL treatment and CST with aPDI) (Table 6). Interestingly, some antimicrobials had synergies with phototreatments, but they were strain-dependent suggesting that no general conclusion concerning the possible synergy could be drawn (i.e., SXT and CST when combined with aBL for A. baumannii nos. 127 and 128, respectively, or IPM and SAM interacting synergistically with aPDI in case of A. baumannii no. 128) (Table 6). As expected, various synergy testing methods detected different synergistic interactions, indicating that the employment of various techniques is mandatory.

\section{Increased ROS Generation Could Explain the Mechanism Underlying the Observed Synergies}

To investigate whether increased ROS production is responsible for the synergies between aBL/aPDI and antimicrobials, the level of ROS generated upon combined treatment was examined for four combined treatments (Figure 6).

As expected, effective ROS generation was observed upon only photodynamic treatment. Interestingly, the level of generated ROS was significantly increased when a combined treatment was employed (Figure 6). The most pronounced increase in ROS generation was reported for the $\mathrm{aBL}$ and $\mathrm{DOX}$ combination 
TABLE 6 | Summarized results of synergy testing.

\begin{tabular}{|c|c|c|c|c|c|c|c|c|c|c|}
\hline \multirow[t]{3}{*}{ Antibiotic } & \multicolumn{10}{|c|}{ A. baumannii 127} \\
\hline & \multicolumn{5}{|c|}{ aBL } & \multicolumn{5}{|c|}{ aPDI } \\
\hline & $E-$ test & $\begin{array}{c}\text { Disk } \\
\text { diffusion }\end{array}$ & $\begin{array}{c}\text { Checkerboard } \\
\text { assay }\end{array}$ & $\begin{array}{l}\text { Survival } \\
\text { rate }\end{array}$ & $\begin{array}{c}\text { Post antibiotic } \\
\text { effect }\end{array}$ & $E$ - test & $\begin{array}{c}\text { Disk } \\
\text { diffusion }\end{array}$ & $\begin{array}{c}\text { Checkerboard } \\
\text { assay }\end{array}$ & $\begin{array}{l}\text { Survival } \\
\text { rate }\end{array}$ & $\begin{array}{c}\text { Post antibiotic } \\
\text { effect }\end{array}$ \\
\hline GEN & + & - & - & $+1-$ & + & - & - & - & - & + \\
\hline DOX & + & + & + & + & + & + & + & - & + & + \\
\hline SXT & - & - & + & + & + & - & - & - & - & + \\
\hline $\mathrm{CIP}$ & - & - & - & + & + & - & - & - & - & - \\
\hline IPM & + & + & - & $+/-$ & + & + & - & - & - & - \\
\hline TZP & - & - & - & + & + & - & - & - & - & $+/-$ \\
\hline CAZ & - & - & - & $+/-$ & - & - & - & - & - & $+/-$ \\
\hline SAM & + & + & - & - & + & - & + & - & - & $+/-$ \\
\hline \multirow[t]{2}{*}{ CST } & - & - & - & + & - & - & + & + & + & + \\
\hline & \multicolumn{10}{|c|}{ A. baumannii 128} \\
\hline GEN & - & + & - & - & $+/-$ & + & - & - & - & - \\
\hline DOX & + & - & + & + & + & + & + & + & + & + \\
\hline $\mathrm{SXT}$ & - & - & - & - & $+/-$ & - & - & - & - & $+/-$ \\
\hline CIP & - & - & - & - & $+/-$ & - & - & - & - & $+1-$ \\
\hline IPM & - & + & - & + & + & + & + & + & - & $+/-$ \\
\hline TZP & - & - & - & - & - & - & + & - & - & - \\
\hline CAZ & - & - & - & - & - & + & - & - & - & - \\
\hline SAM & + & - & - & $+1-$ & + & + & + & - & $+/-$ & - \\
\hline CST & - & + & - & + & + & - & + & + & + & $+/-$ \\
\hline
\end{tabular}

CAZ, ceftazidime; CIP, ciprofloxacin; CST, colistin; DOX, doxycycline; GEN, gentamycin; IPM, imipenem; SAM, ampicillin-sulbactam; SXT, trimethoprim-sulfamethoxazole; TZP, piperacillin-tazobactam.

(Figure 6A), but a similar effect was observed for all studied combined approaches. This discovery supported one of several possible mechanisms underlying the observed synergies.

\section{DISCUSSION}

The most recent discoveries concerning combinations of aBL/ aPDI and antibiotics indicate that photoinactivation sensitizes microorganisms to routinely used antimicrobials [most recently reviewed by Wozniak and Grinholc (2018)]. If it is confirmed with the employment of approved methodology and translated into in vivo and clinical applications, this approach could improve the clinical outcome of i.e., wound infections caused by MDR pathogens and might reduce usage of antibiotics in the long term. Only a limited number of methodologies are adequate for investigation of synergistic interactions between various antibacterial approaches. This recommendation explains the employment of all the indicated methods within the current study. Moreover, the current study is the first to describe aBL/aPDI interactions with antimicrobials covering all antibiotic categories as well as all antimicrobial mechanisms of action.

The significant bactericidal efficacy of both aBL and aPDI against $A$. baumannii was repeatedly reported in numerous published in vitro and in vivo studies (Dai et al., 2009; Huang et al., 2014; Maisch et al., 2014; Zhang et al., 2014;
Yuan et al., 2017; Yang et al., 2018). However, the first published evidence of a combined aPDI/antibiotic approach being used against pandrug-resistant $A$. baumannii was presented by Boluki et al. (2017). Their research evidenced that aPDI affects the expression level of genes responsible for Acinetobacter resistance to colistin, i.e., $p m r A$ and $p m r B$. In the case of other microbial species, the enhanced bacterial killing of the combined approach was frequently reported using in vitro planktonic (Almeida et al., 2014; Fila et al., 2017; Branco et al., 2018) biofilm (Perez-Laguna et al., 2017; Zhang et al., 2017) and in vivo models (Lu et al., 2010; Chibebe et al., 2013). The mentioned studies indicate that employing various culture media and experimental conditions, one could report different results; thus, it is mandatory to utilize standardized and approved methodology for synergy testing, which was the issue of prime importance within the current study.

The mechanisms underlying aBL/aPDI and antimicrobial interactions have never been identified, although some hypotheses have already been drawn (Wozniak and Grinholc, 2018). First, the synergistic effects may result from the increased permeability of the cell envelope resulting from aBL/aPDIinduced damage of this structure, which leads to increased antibiotic uptake into bacterial cells (Hewelt-Belka et al., 2016; Kossakowska-Zwierucho et al., 2016; Dai, 2017). Another possible mechanism could be the oxidative stress resulting from photochemical reactions and inhibiting the expression 

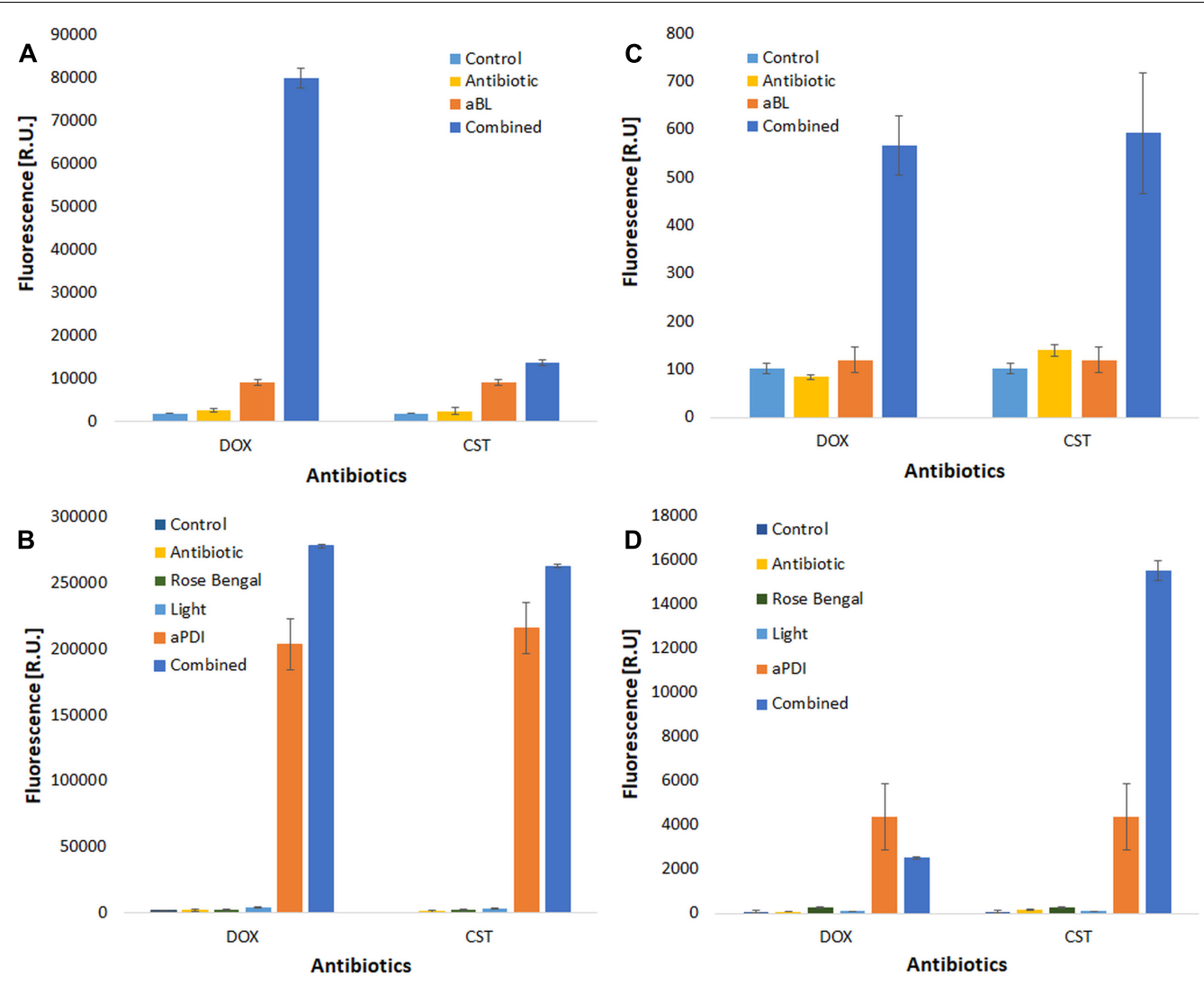

FIGURE 6 | ROS detection. ROS detection was performed for two antimicrobials (doxycycline, DOX and colistin, CST). Cell-free suspensions of antimicrobials and/or rose bengal were incubated with ROS-detecting fluorescent probes to detect hydroxyl radicals $(\bullet \mathrm{OH})[\mathrm{panels}(\mathbf{A})$ aBL treatment, and $(\mathbf{B})$ aPDI treatment] and singlet oxygen [(C) aBL treatment, and (D) aPDI treatment] upon irradiation. The values are the means of three separate experiments.

of genes determining microbial drug resistance (Boluki et al., 2017). Furthermore, the high bactericidal efficacy of combined approach can be explained by the fact that PSs can be substrates for efflux pumps. This competition between PSs and antimicrobials leads to increased uptake of antibiotics after the permeabilization of bacterial cell envelopes (Shih and Huang, 2011). In addition and most recently, He et al. (2018) published results confirming that some antimicrobials may express dual activity (He et al., 2018). They reported that tetracyclines may function as dual-action light-activated antibiotics expressing photosensitizing activity; this phenomenon may thus explain the synergy between aBL/aPDI and DOX within the current study. Another possible explanation for the combined treatment synergy could be concluded from the fact that both aBL/aPDI and antibiotic treatments lead to increased ROS production (Van Acker and Coenye, 2017); thus, phototherapy may lead to increased bactericidal efficacy and synergy via potentiation of the oxidative stress induced by antibiotic administration. It is only a hypothesis, as the mediation of ROS by antibiotic action has been an issue of concern in numerous literature studies. Within the current study, an effort was made to determine the role of ROS in the enhanced bacterial killing by combined treatments. The obtained data confirmed that increased ROS generation occur upon combined aBL/aPDI and antimicrobial treatment, indicating a possible explanation for the mechanism underlying this interaction.

\section{CONCLUSION}

The described above issues indicate possible explanations for increased bactericidal efficacy of aBL/aPDI and antimicrobials when administered in combination; thus, the development of an alternative combined aBL/aPDI and antibiotics treatment seems to be justified and desired. The combined approach results not only in increased antimicrobial efficacy of but also decreased concentrations of antimicrobials, which may greatly slow the increasing rate of drug resistance (Dai, 2017).

\section{ETHICS STATEMENT}

All isolated strains were collected during routine sampling. The current study only describes a collection of bacteria that comprised strains obtained from patients. Data collected from patients were anonymized and restricted to the information of the type of specimen and infection the strains were isolated from. Ethical approval was therefore not required. Moreover, the manuscript contains no data concerning animal studies, 
studies involving human subjects or inclusion of identifiable human data or clinical trials; thus, no ethical approval was required.

\section{AUTHOR CONTRIBUTIONS}

AW did the experimental work and participated in conception of the study. AR-Z performed studies concerning rose Bengal checkerboard analysis. NM participated in the data interpretation

\section{REFERENCES}

Almeida, J., Tome, J. P., Neves, M. G., Tome, A. C., Cavaleiro, J. A., Cunha, A., et al. (2014). Photodynamic inactivation of multidrug-resistant bacteria in hospital wastewaters: influence of residual antibiotics. Photochem. Photobiol. Sci. 13, 626-633. doi: 10.1039/c3pp50195g

Amin, R. M., Bhayana, B., Hamblin, M. R., and Dai, T. (2016). Antimicrobial blue light inactivation of Pseudomonas aeruginosa by photo-excitation of endogenous porphyrins: in vitro and in vivo studies. Lasers Surg. Med. 48, 562-568. doi: 10.1002/lsm.22474

Andersson, D. I., and Hughes, D. (2014). Microbiological effects of sublethal levels of antibiotics. Nat. Rev. Microbiol. 12, 465-478. doi: 10.1038/nrmicro3270

Barry, A. L., and Lasner, R. A. (1979). In-vitro methods for determining minimal lethal concentrations of antimicrobial agents. Am. J. Clin. Pathol. 71, 88-92. doi: 10.1093/ajcp/71.1.88

Boluki, E., Kazemian, H., Peeridogaheh, H., Alikhani, M. Y., Shahabi, S., Beytollahi, L., et al. (2017). Antimicrobial activity of photodynamic therapy in combination with colistin against a pan-drug resistant Acinetobacter baumannii isolated from burn patient. Photodiagnosis Photodyn. Ther. 18, 1-5. doi: 10. 1016/j.pdpdt.2017.01.003

Branco, T. M., Valerio, N. C., Jesus, V. I. R., Dias, C. J., Neves, M., Faustino, M. A. F., et al. (2018). Single and combined effects of photodynamic therapy and antibiotics to inactivate Staphylococcus aureus on skin. Photodiagnosis Photodyn. Ther. 21, 285-293. doi: 10.1016/j.pdpdt.2018.01.001

Cai, Y., Chai, D., Wang, R., Liang, B., and Bai, N. (2012). Colistin resistance of Acinetobacter baumannii: clinical reports, mechanisms and antimicrobial strategies. J. Antimicrob. Chemother. 67, 1607-1615. doi: 10.1093/jac/dks084

Chibebe, J. J., Fuchs, B. B., Sabino, C. P., Junqueira, J. C., Jorge, A. O., Ribeiro, M. S., et al. (2013). Photodynamic and antibiotic therapy impair the pathogenesis of Enterococcus faecium in a whole animal insect model. PLoS One 8:e55926. doi: 10.1371/journal.pone.0055926

Dai, T. (2017). The antimicrobial effect of blue light: what are behind? Virulence 8, 649-652. doi: 10.1080/21505594.2016.1276691

Dai, T., Tegos, G. P., Lu, Z., Huang, L., Zhiyentayev, T., Franklin, M. J., et al. (2009). Photodynamic therapy for Acinetobacter baumannii burn infections in mice. Antimicrob. Agents Chemother. 53, 3929-3934. doi: 10.1128/AAC.00027-09

Dodd, C. E. R., Sharman, R. L., Bloomfield, S. F., Booth, I. R., and Stewart, G. S. A. B. (1997). Inimical processes: bacterial self-destruction and sub-lethal injury. Trends Food Sci. Technol. 8, 238-241. doi: 10.1016/S0924-2244(97)01043-1

Doern, C. D. (2014). When does 2 plus 2 equal 5? A review of antimicrobial synergy testing. J. Clin. Microbiol. 52, 4124-4128. doi: 10.1128/JCM.01121-14

Fila, G., Kawiak, A., and Grinholc, M. S. (2017). Blue light treatment of Pseudomonas aeruginosa: strong bactericidal activity, synergism with antibiotics and inactivation of virulence factors. Virulence 8, 938-958. doi: 10.1080/21505594.2016.1250995

Fila, G., Krychowiak, M., Rychlowski, M., Bielawski, K. P., and Grinholc, M. (2018). Antimicrobial blue light photoinactivation of Pseudomonas aeruginosa: quorum sensing signaling molecules, biofilm formation and pathogenicity. J. Biophotonics 11:e201800079. doi: 10.1002/jbio.201800079

Grinholc, M., Rodziewicz, A., Forys, K., Rapacka-Zdonczyk, A., Kawiak, A., Domachowska, A., et al. (2015). Fine-tuning recA expression in Staphylococcus aureus for antimicrobial photoinactivation: importance of photo-induced DNA damage in the photoinactivation mechanism. Appl. Microbiol. Biotechnol. 99, 9161-9176. doi: 10.1007/s00253-015-6863-z and critical manuscript review. MG has been involved in the coordination, conception, and design of the study and wrote the manuscript. All of the authors have read and approved the final manuscript.

\section{FUNDING}

This work was supported by Narodowe Centrum Nauki (Grant No. NCN 2015/19/B/NZ7/02487 to MG).

He, Y., Huang, Y. Y., Xi, L., Gelfand, J. A., and Hamblin, M. R. (2018). Tetracyclines function as dual-action light-activated antibiotics. PLoS One 13:e0196485. doi: 10.1371/journal.pone.0196485

Hewelt-Belka, W., Nakonieczna, J., Belka, M., Baczek, T., Namiesnik, J., and KotWasik, A. (2016). Untargeted lipidomics reveals differences in the lipid pattern among clinical isolates of staphylococcus aureus resistant and sensitive to antibiotics. J. Proteome Res. 15, 914-922. doi: 10.1021/acs.jproteome.5b00915

Huang, L., Wang, M., Dai, T., Sperandio, F. F., Huang, Y. Y., Xuan, Y., et al. (2014). Antimicrobial photodynamic therapy with decacationic monoadducts and bisadducts of [70]fullerene: in vitro and in vivo studies. Nanomedicine 9, 253-266. doi: 10.2217/nnm.13.22

Kohanski, M. A., Depristo, M. A., and Collins, J. J. (2010). Sublethal antibiotic treatment leads to multidrug resistance via radical-induced mutagenesis. Mol. Cell 37, 311-320. doi: 10.1016/j.molcel.2010.01.003

Kossakowska-Zwierucho, M., Kazmierkiewicz, R., Bielawski, K. P., and Nakonieczna, J. (2016). Factors determining staphylococcus aureus susceptibility to photoantimicrobial chemotherapy: RsbU activity, staphyloxanthin level, and membrane fluidity. Front. Microbiol. 7:1141. doi: 10.3389/ fmicb.2016.01141

Latimer, J., Forbes, S., and Mcbain, A. J. (2012). Attenuated virulence and biofilm formation in Staphylococcus aureus following sublethal exposure to triclosan. Antimicrob. Agents Chemother. 56, 3092-3100. doi: 10.1128/AAC. 05904-11

Lu, Z., Dai, T., Huang, L., Kurup, D. B., Tegos, G. P., Jahnke, A., et al. (2010). Photodynamic therapy with a cationic functionalized fullerene rescues mice from fatal wound infections. Nanomedicine 5, 1525-1533. doi: 10.2217/nnm. 10.98

Magiorakos, A. P., Srinivasan, A., Carey, R. B., Carmeli, Y., Falagas, M. E., Giske, C. G., et al. (2012). Multidrug-resistant, extensively drug-resistant and pandrug-resistant bacteria: an international expert proposal for interim standard definitions for acquired resistance. Clin. Microbiol. Infect. 18, 268-281. doi: 10.1111/j.1469-0691.2011.03570.x

Maisch, T. (2015). Resistance in antimicrobial photodynamic inactivation of bacteria. Photochem. Photobiol. Sci. 14, 1518-1526. doi: 10.1039/c5pp00037h

Maisch, T., Eichner, A., Spath, A., Gollmer, A., Konig, B., Regensburger, J., et al. (2014). Fast and effective photodynamic inactivation of multiresistant bacteria by cationic riboflavin derivatives. PLoS One 9:e111792. doi: 10.1371/journal. pone.0111792

Nitzan, Y., Balzam-Sudakevitz, A., and Ashkenazi, H. (1998). Eradication of Acinetobacter baumannii by photosensitized agents in vitro. J. Photochem. Photobiol. B 42, 211-218. doi: 10.1016/S1011-1344(98)00073-6

Odds, F. C. (2003). Synergy, antagonism, and what the chequerboard puts between them. J. Antimicrob. Chemother. 52:1. doi: 10.1093/jac/dkg301

Odenholt, I. (2001). Pharmacodynamic effects of subinhibitory antibiotic concentrations. Int. J. Antimicrob. Agents 17, 1-8. doi: 10.1016/S0924-8579(00) 00243-0

Ogonowska, P., Woźniak, A., Pierański, M., Wasylew, T., Kwiek, P., Brasel, M., et al. (2018). Application and characterization of light-emitting diodes for photodynamic inactivation of bacteria. Lighting Res. Technol. doi: 10.1177/ 1477153518781478

Perez-Laguna, V., Perez-Artiaga, L., Lampaya-Perez, V., Garcia-Luque, I., Ballesta, S., Nonell, S., et al. (2017). Bactericidal effect of photodynamic therapy, alone or in combination with mupirocin or linezolid, on Staphylococcus aureus. Front. Microbiol. 8:1002. doi: 10.3389/fmicb.2017.01002 
Price, M., Reiners, J. J., Santiago, A. M., and Kessel, D. (2009). Monitoring singlet oxygen and hydroxyl radical formation with fluorescent probes during photodynamic therapy. Photochem. Photobiol. 85, 1177-1181. doi: 10.1111/j. 1751-1097.2009.00555.x

Shih, M. H., and Huang, F. C. (2011). Effects of photodynamic therapy on rapidly growing nontuberculous mycobacteria keratitis. Invest. Ophthalmol. Vis. Sci. 52, 223-229. doi: 10.1167/iovs.10-5593

Spellberg, B., and Bonomo, R. A. (2014). The deadly impact of extreme drug resistance in Acinetobacter baumannii. Crit. Care Med. 42, 1289-1291. doi: 10.1097/CCM.0000000000000181

Valencia, R., Arroyo, L. A., Conde, M., Aldana, J. M., Torres, M. J., FernandezCuenca, F., et al. (2009). Nosocomial outbreak of infection with pan-drugresistant Acinetobacter baumannii in a tertiary care university hospital. Infect. Control Hosp. Epidemiol. 30, 257-263. doi: 10.1086/595977

Van Acker, H., and Coenye, T. (2017). The role of reactive oxygen species in antibiotic-mediated killing of bacteria. Trends Microbiol. 25, 456-466. doi: 10. 1016/j.tim.2016.12.008

Wainwright, M. (1998). Photodynamic antimicrobial chemotherapy (PACT). J. Antimicrob. Chemother. 42, 13-28. doi: 10.1093/jac/42.1.13

Wozniak, A., and Grinholc, M. (2018). Combined antimicrobial activity of photodynamic inactivation and antimicrobials-state of the art. Front. Microbiol. 9:930. doi: 10.3389/fmicb.2018.00930

Yang, M. Y., Chang, K. C., Chen, L. Y., Wang, P. C., Chou, C. C., Wu, Z. B., et al. (2018). Blue light irradiation triggers the antimicrobial potential of $\mathrm{ZnO}$ nanoparticles on drug-resistant Acinetobacter baumannii. J. Photochem. Photobiol. B 180, 235-242. doi: 10.1016/j.jphotobiol.2018.02.003
Yuan, Y., Liu, Z. Q., Jin, H., Sun, S., Liu, T. J., Wang, X., et al. (2017). Photodynamic antimicrobial chemotherapy with the novel amino acid-porphyrin conjugate $4 \mathrm{I}$ : in vitro and in vivo studies. PLoS One 12:e0176529. doi: 10.1371/journal.pone. 0176529

Zhang, Q. Z., Zhao, K. Q., Wu, Y., Li, X. H., Yang, C., Guo, L. M., et al. (2017). 5-aminolevulinic acid-mediated photodynamic therapy and its strain-dependent combined effect with antibiotics on Staphylococcus aureus biofilm. PLoS One 12:e0174627. doi: 10.1371/journal.pone. 0174627

Zhang, Y., Zhu, Y., Gupta, A., Huang, Y., Murray, C. K., Vrahas, M. S., et al. (2014). Antimicrobial blue light therapy for multidrug-resistant Acinetobacter baumannii infection in a mouse burn model: implications for prophylaxis and treatment of combat-related wound infections. J. Infect. Dis. 209, 1963-1971. doi: 10.1093/infdis/jit842

Conflict of Interest Statement: The authors declare that the research was conducted in the absence of any commercial or financial relationships that could be construed as a potential conflict of interest.

Copyright (c) 2019 Wozniak, Rapacka-Zdonczyk, Mutters and Grinholc. This is an open-access article distributed under the terms of the Creative Commons Attribution License (CC BY). The use, distribution or reproduction in other forums is permitted, provided the original author(s) and the copyright owner(s) are credited and that the original publication in this journal is cited, in accordance with accepted academic practice. No use, distribution or reproduction is permitted which does not comply with these terms. 